\title{
René Pommier, Sanglades
}

\section{Fatima Pilone}

\section{(2) OpenEdition}

\section{Journals}

\section{Edizione digitale}

URL: http://journals.openedition.org/studifrancesi/9721

DOI: ERREUR PDO dans /localdata/www-bin/Core/Core/Db/Db.class.php L.34 : SQLSTATE[HY000]

[2006] MySQL server has gone away

ISSN: 2421-5856

\section{Editore}

Rosenberg \& Sellier

\section{Edizione cartacea}

Data di pubblicazione: 1 décembre 2007

Paginazione: 712

ISSN: 0039-2944

\section{Notizia bibliografica digitale}

Fatima Pilone, «René Pommier, Sanglades», Studi Francesi [Online], 153 (LI | III) | 2007, online dal 30 novembre 2015, consultato il 07 janvier 2021. URL: http://journals.openedition.org/studifrancesi/9721 ; DOI: https://doi.org/ERREUR PDO dans /localdata/www-bin/Core/Core/Db/Db.class.php L.34: SQLSTATE[HY000] [2006] MySQL server has gone away

\section{Questo documento è stato generato automaticamente il 7 janvier 2021.}

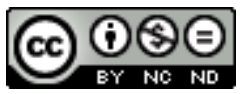

Studi Francesi è distribuita con Licenza Creative Commons Attribuzione - Non commerciale - Non opere derivate 4.0 Internazionale. 


\title{
René Pommier, Sanglades
}

\author{
Fatima Pilone
}

\section{NOTIZIA}

RENÉ POMMIER, Sanglades, Paris, Eurédit, 2006, pp. 123.

1 Gli scritti di René Pommier qui raccolti sono segnati da una collera vendicatrice, come dimostra in primo luogo il titolo, il cui campo semantico di riferimento include aggressività e violenza. Avversario risoluto della 'nouvelle critique', Prix de la Critique de l'Académie Française nel 1979 con Assez décodé!, l'autore riunisce in questo piccolo volume quattro articoli (solo il primo risulta precedentemente pubblicato in una versione più ampia). Denominatore comune, afferma, la collera.

In Nouvelle Stylistique ou nouvelle imposture, Pommier attacca Georges Molinié, professore di stilistica ed ex preside dell'Università Paris-Sorbonne, al quale Pommier imputa il grave errore di presentare fondamentali dei testi, tra cui proprio i suoi, in realtà totalmente inutili. Non c'è bisogno, secondo Pommier, di aver fatto studi di stilistica per apprezzare a pieno Bossuet o Chateaubriand. Molinié parla di sémiostylistique, attingendo nei suoi lavori alla stilistica e alla semiotica. Ma per Pommier non è sufficiente conoscere uno schema semiotico o attanziale, conoscere un termine tecnico, per designare un determinato procedimento stilistico o per comprenderlo pienamente, essendo invece la vera e propria analisi a permettere di coglierne il significato profondo. La nouvelle stylistique dice con un lessico difficile ed ampolloso e con grafici spesso poco accessibili, considerati dall'autore lapalissiani, cose che si potrebbero tranquillamente dire in modo molto più semplice. Non c'è motivo, secondo Pommier, per dire con sigle, simboli e frecce, come avviene negli schemi creati da Greimas in semiotica, quello che si potrebbe dire a parole, in modo sicuramente più comprensibile e diretto. La nouvelle stylistique diventa per Pommier uno strumento per fare letteratura in mano a coloro che sono privi di una sensibilità letteraria.

3 Ne Le Théâtre expliqué par la mère Ubu, l'autore analizza l'ultima edizione in tre volumi di Lire le théâtre di Anne Ubersfeld, considerata da molti in ambito universitario come una 
delle più grandi specialiste di studi sul teatro ma la cui scrittura è invece considerata da Pommier rebutante. Il testo che per i suoi sostenitori è fondamentale nell'approccio allo studio delle forme teatrali, è per l'autore invece inepte e indigeste. Per lui, la studiosa ha una conoscenza approssimativa persino delle più celebri opere, commedie o tragedie che siano, del teatro francese.

4 Con La Pédagogie contre l'enseignement, Pommier attacca quella che definisce una vera e propria setta capitanata dal guru Philippe Meirieu: a un insegnamento malato, essi, insieme con gli esponenti del Ministero dell'Educazione Nazionale, pongono come rimedio la pedagogia, vedendo nel 1968 il suo anno di nascita. Per Pommier quello è stato in realtà l'anno che ha segnato per l'insegnamento l'inizio della fine. La formazione pedagogica è la rovina dell'insegnamento, a causa di stages nelle scuole troppo brevi e di programmi di lavoro insensati. Il motto dei sostenitori di un approccio pedagogico è Faire classe sans faire cours, dando voce agli allievi, ma per l'autore la vera preoccupazione dovrebbe essere quella di non accontentarsi di testi che forniscono commenti sommari e semplicistici. La padronanza della disciplina è oggi considerata meno importante della formazione pedagogica ed è questa la causa del declino dell'insegnamento stesso.

Infine, Le Français en capitolade, parla della distruzione della lingua francese in parte come conseguenza dei temi affrontati nelle sezioni precedenti. Citando l'universitario americano R.-J. Berg, Pommier denuncia il crimine che non può perdonare ai francesi: le sabotage de la langue, da parte di giornalisti, uomini politici, personalità dello spettacolo, i primi a far propagare gli errori di francese.

6 Ne consegue un impoverimento sempre maggior del vocabolario medio, che si cerca di aggirare attraverso il gusto per frasi alambiquées et calamiteuses, a scapito di enunciati concisi e chiari. La vera malattia di cui soffre la lingua è per l'autore il massacro della sintassi.

7 Pommier conclude l'articolo, e con esso l'intero volume, prendendo in prestito quanto asserito da Claude Duneton nel suo La mort du français: «il faudrait agir vite. Ne pas attendre le point de non retour, l'irrécupérable état d'une langue déchue». A fronte di questo, Pommier non lascia tuttavia spazio a molta speranza, dando a intendere al lettore che quel punto di non ritorno è in realtà ormai stato raggiunto, e superato. 